\title{
O ESPAÇO RELACIONAL, A QUESTÃO URBANA E O SUJEITO QUE GEO-GRAFIA O MUNDO NO PENSAMEMTO DE JËRÔME MONNET
}

\begin{abstract}
Raimundo Freitas Aragão ${ }^{1}$
Resumo: Os geógrafos, como qualquer outro cientista social ou humano, estão constantemente procurando estabelecer novas leituras sobre o mundo e seus habitantes. São desafios perenes pelo motivo de estarem em mudança e evolução. Se o espaço, a cidade/urbano e o sujeito em comum são uma sucessão de heterogeneidades produtoras de territorialidades, ocorrendo em uma constância indefinida, a geografia se posiciona em procurar meios para desvendar os labirintos que se formam. O geógrafo Jèrôme Monnet propõe apreender esta complexa trama em sua dinâmica ao elaborar sua própria concepção de espaço, compreensão esta que vai dar forma à teoria da interpretação-ordenamento do espaço urbano.
\end{abstract}

Palavras-chave: Jèrôme Monnet; Espaço relacional; Cidade; Urbano

\section{THE RELATIONAL SPACE, THE URBAN QUESTION AND THE SUBJECT WHO GEO-GRAPHY THE WORLD BY JËRÔME MONNET'S THOUGHT}

\begin{abstract}
Geographers, like any other social or human scientist, are constantly looking to establish new readings about the world and its inhabitants. They are in permanent challenges for the reason that world and inhabitant are changing and evolving. If the space, the city/urban and the subject all in common are a succession of heterogeneities producing territorialities occurring in an undefined way, geography must look for methods to unravel the labyrinths of it. Jèrôme Monnet proposes to grasp this complex plot in its dynamics to develop his own conception of space, an understanding that will form the theory of interpretation-planning of the urban space.
\end{abstract}

Key words: Jèrôme Monnet; Relational space; City; Urban

\section{EL ESPACIO RELACIONAL, LA CUESTIÓN URBANA Y EL SUJETO QUE GEO- GRAFÍA EL MUNDO EN EL PENSAMIENTO DE JÉRÔME MONNET}

Resumen: Los geógrafos, como cualquier otro científico social o humano, están constantemente en busca de establecer nuevas lecturas sobre el mundo y sus habitantes. Son desafíos constantes por el motivo de estar en cambio y evolución. Si el espacio, la ciudad / urbano y el sujeto en común son una sucesión de heterogeneidades productoras de territorialidades, ocurriendo en una constancia indefinida, la geografía se posiciona en buscar medios para descubrir los laberintos que se forman. El geógrafo Jèrôme Monnet propone aprehender esta compleja trama en su dinámica al elaborar su propia concepción de espacio, entendimiento que va a dar forma a la teoría de la interpretación-ordenación del espacio urbano.

Palabras clave: Jèrôme Monnet; Espacio relacional; Ciudad; Urbano

\footnotetext{
${ }^{1}$ Pós-doutor em Geografia Humana pela Universidade Federal do Ceará. Email: ararageo2007@ yahoo.com.br
} 


\section{Introdução}

O conjunto cidade-urbano é objeto onipresente de pesquisas em diferentes disciplinas e vem sendo trabalhado nas mais variadas perspectivas. Trata-se de tema rico e ao mesmo tempo complexo para as diferentes correntes epistemológicas que mergulham na busca em compreender as intrincadas dinâmicas que lhe estão subjacentes. Para a geografia, este conjunto é crucial, pois encontram-se nele os elementos os quais fornecem a compreensão das principais categorias conceituais da disciplina, como exemplo o do espaço, categoria mais ampla, a do território, a da paisagem e a do lugar, a mais específica. Estas categorias conceituais são dinâmicas, daí toda sua complexidade. A cidade e o urbano são construídos pela sociedade que neles se desenvolvem, pela interpretação-ordenamento que deles fazem seus moradores em sociedade.

O que apresentamos neste artigo é um apanhado teórico sobre a cidade e o urbano baseado nas ideias e reflexões do geógrafo Jèrôme Monnet englobando algumas de suas obras. A importância desse geógrafo se faz pela clareza de seu pensamento crítico, o que permite pensar a cidade e o urbano contemporâneos em sua multiplicidade, ou seja, suas dimensões humana e social mais amplas a partir das relações socioespaciais. Acreditamos que seu pensamento aponta um caminho original sobre a realidade da cidade e do urbano no mundo contemporâneo, o que marca o caráter do trabalho acadêmico não só para a geografia, também como para disciplinas afins.

Jèrôme Monnet é $\mathrm{PhD}$ em Geografia Cultural pela Universidade de Paris IV desde 1992. Especialista em ordenamento urbano, representações e ações geográficas, espaço público, centralidade e espaço público, metropolização, globalização e cidadania. É professor da Escola de Urbanismo de Paris e pesquisador sênior do Lab'Urba da Universidade de ParisEst. Membro fundador do Research Group on Urban Pedestrian Mobility. Estuda a produção social do espaço público tendo como campo de pesquisa as cidades do México, Paris e Los Ângeles e cujo foco são as dimensões do espaço popular/ou práticas informais e políticas do mercado de rua, acesso de mobilidade e wall comunication, ou seja, arte de rua, graffiti e propaganda. É coeditor da Espaces et Societés, revista eletrônica científica centrada nas relações entre a sociedade e seus espaços. 
Em se tratando de uma pesquisa bibliográfica, a metodologia adotada foi a de pesquisa qualitativa concentrada na leitura e análise de obras do autor contextualmente referenciadas, já que a pesquisa qualitativa permite dar conta de conceituações e de objetos analisados.

O trabalho está estruturado em quatro partes: na primeira Monnet discorre sobre o seu conceito de espaço relacional e o remete à questão urbana apresentando reflexões sobre interpretação-ordenamento e a problemática envolvendo os atores tomadores de decisão urbanos. Na segunda, ele põe em foco as relações necessárias para se compreender a diferença entre urbanismo e urbanidade para o entendimento da cidade como "Objeto Sócio Espacial Identificável". Na terceira parte, centraliza discussão do sujeito em geografia, elaborando uma crítica sobre a escala geográfica que não consegue alcançá-lo. Na última, trata da das consciências geográficas e da cognição na cidade como importantes para novas pesquisas envolvendo a cidade e o urbano, apresentando exemplos possíveis de pesquisas nos diversos campos da disciplina com a colaboração de ciências afins.

\section{Por um espaço e uma geografia das relações dos atores sociais}

Procurar e estabelecer novas abordagens de leitura sobre o espaço, a cidade/ urbano e o sujeito são desafios constantes para a geografia pelo motivo deles estarem em constante evolução. Se cidade/urbano é uma sucessão de heterogeneidades e territorialidades ocorrendo em uma constância indefinida, a geografia tem que procurar meios para desvendar os labirintos que nela se formam. Monnet (1999a), ao propor apreender a cidade e o urbano em sua dinâmica elabora a concepção de espaço, concepção esta que vai dar forma à sua teoria a qual propõe compreender as tramas e as tessituras que envolvem o ordenamento espacial da cidade. Espaço para ele é, então:

[...] a matéria das relações. Ele constitui a matéria da relação do sujeito ao objeto, de si para o outro, de nós a eles, do interior ao exterior, da consciência ao mundo. Que o espaço seja concebido em uma perspectiva objetiva, subjetiva ou trajetiva, ele aparece sempre como condição da relação. Que se trate de consciência, de conhecimento ou de comunicação: é necessário que aí tenha diferenciação e distância. (MONNET, 1999ª p. 126. Grifo nosso).

O termo "relação" em destaque encobre todo processo de ordenamento espacial urbano. Essa sua ideia de relação dos acontecimentos no espaço vai culminar no que ele chama de "interpretação-ordenamento2" do espaço, como tentativa de situar seu arcabouço

\footnotetext{
${ }^{2}$ Apresentamos aqui o que Augustin Berque (1995) diz sobre interpretação: "as sociedades ordenam seu ambiente em função das interpretações que dele fazem. E reciprocamente elas o interpretam em função do ordenamento que nele realizam". Ou seja, a interpretação "[...] designa aqui tanto as maneiras de ver quanto as maneiras de dizer [...]". (BERQUE, 1995, p. 15).
} 
teórico diferenciando-se do que cientistas sociais e mesmo geógrafos chamam de "representação-ação" do espaço, como ele próprio indica. Sua intenção é demonstrar que o modelo teórico "interpretação-ordenamento", pode ser utilizado como uma "performance" geográfica por excelência. A teoria é aplicada ao mundo urbano, no sentido de entender a cidade como um cosmos, ou seja, uma complexidade organizada de mundos particulares e diretamente experimentada por seus habitantes.

Ele busca apoio intelectual em quatro autores para dar suporte à sua teoria, a saber: Augustin Berque, Guy Di Méo; Jacques Lévy e Régis Debray. Estes autores são essenciais por que, a partir deles, Monnet (1999a) trata o espaço como um "médium", ou seja, a relação existente entre o ser humano e o mundo. Assim o mundo aparece como uma "relação" conforme destacado. Os axiomas abaixo vão definir sua posição. Ele busca, por isso: A "mesologia" definida como a "disciplina que se ocupa dos meios humanos e do ecúmeno, para definir a médiance". Esta é procedente da aliança entre geografia e fenomenologia e inspirada no geógrafo orientalista e fenomenólogo Augustin Berque; A "territorialidade mediadora" ou "mediação-sócio-espacial": este qualificaria os lugares segundo a posição que eles têm na passagem da identidade à alteridade, do conhecido ao desconhecido, do familiar ao estrangeiro, da mudança ao silêncio. Este é inspirado no geógrafo social Guy Di Meo; A "geografia da política", pois esta daria conta das condições da "co-presença" e das "mediações" territorializadas do "viver juntos em comum". Inspirado no geógrafo Jacques Lévy e; A “mediologia” ilustrada no filósofo mediólogo Régis Debray e apresentada como "a ecologia das representações ou das ideias eficazes", inspirada no também filósofo mediólogo Daniel Bougnoux.

Estes autores, cujos axiomas o inspiraram, são denominados por ele de autores relacionais, pois os considera adeptos do seguinte pensamento: a realidade não é construída em termos de oposição dualista absolutista, cuja característica é de produzir determinismos de sentido único, a exemplo do mundo objetivo separado categoricamente do mundo subjetivo. Por isso a junção dos axiomas estabeleceria o espaço em processo de "relação" (ou médiance). Desse modo, Para Monnet a "realidade" seria um conjunto, ou seja, a totalidade das relações entre temas, fatos, ditos, conceitos, matéria, espírito, lugares etc. Para justificar esta posição de autor relacional a respeito da(s) realidade(s), ele constrói o seguinte postulado:

As diferentes categorias de realidades são "reais" senão relativamente ao conjunto da realidade como totalidade, senão em relação às outras realidades: a matéria como as ideias deixam de ser realidades para se tornarem irreais logo que elas são abstratas de outras realidades. O ato de abstração em si mesmo não existe fora do mundo: não que não existam espíritos "puros" (isto é, pensamentos não encarnados nas realidades 
psíquicas), que não existam objetos "puros" (isto é, realidades físicas não categorizadas pelo pensamento). Certamente, a matéria tem uma existência autônoma em relação ao pensamento que temos dela, também como as ideias têm sua parte de autonomia. É, além disso, a autonomia da matéria que obriga a nos adaptar (fisicamente e mentalmente) ao mundo, do mesmo modo a autonomia do pensamento (graças à comunicação interindividual) nos autoriza a adaptar o mundo (fisicamente e mentalmente) a nós. [...] o relativismo identifica determinações cruzadas que formam as condições nas quais jogarão o acaso, a necessidade e a vontade (MONNET, 1999a, p. 94).

Neste sentido articula a realidade humana constituída na relação dialética sujeito/objeto nos seguintes termos: de um lado, o sujeito é aquele tal qual se identifica por si próprio, é o ser-no-mundo, atributo da fenomenologia existencial e, de outro lado, o objeto é aquele tal qual como é identificado ou apreendido pelo sujeito. Assim, nas condições as quais ocorre a relação sujeito-mundo, o mundo é um ambiente quando o sujeito o toma como "exterioridade", o mundo é objeto material envolvedor deste sujeito e do qual o sujeito é parte integrante. Então, para ele, a “[...] noção de meio se presta muito a uma perspectiva processual ou relacional, porque não há meio no absoluto, somente meios de qualquer coisa. O ser humano está no meio de seu meio, sendo ele próprio meio de outras coisas [...]" (MONNET, 1999a, p. 133) [grifo do autor].

Para ele, a realidade humana não é construída apenas por meio de um único termo, mas na relação entre todos eles e que, o ordenamento do espaço, é uma interpretação que o sujeito ou os sujeitos sociais fazem do mundo. Dessa forma, o ordenamento espacial passa a ser conceituado como toda ação individual ou coletiva organizadora da "matéria" no espaço e, além do mais, não importando a escala. Isto porque na relação que se estabelece entre sujeitomundo, o sujeito é uma realidade que transforma efetiva e materialmente o mundo. De outro lado, o mundo também é uma realidade, mas essa realidade é vista a partir da concepção do sujeito em relação ao mundo. E aqui apresenta uma das suas mais significativas reflexões qual seja: a noção de interpretação tem duplo sentido capaz de dar conta da retrodeterminação entre ordenamento do espaço e representação do mundo. A interpretação é apresentada de duas formas para o geógrafo: a passiva e a ativa. A primeira contempla aquelas realidades as quais o(s) sujeito(s) tem algo a interpretar, ou melhor, a de compreender e (re)tratar os ordenamentos e representações que lhes são pré-existentes. Já a segunda o(s) sujeito(s), agindo de acordo com suas interpretações do mundo, produzem suas próprias interpretações e também as do mundo.

Ele está de acordo que a cidade pode ser referenciada e diferenciada em dois modelos: "a cidade tal qual deveria ser" e "a cidade tal qual como se encontra" (MONNET, 1999a). Os termos são bastante próximos, porém existe uma sutil e importante diferença entre eles. A 
"cidade tal qual deveria ser", é a cidade na escala da "humanidade". A cidade na escala da humanidade é a cidade de agora, a cidade que está acontecendo neste momento, na ebulição dos diversos sujeitos e atores no poder, é a cidade comandada ou controlada. É a cidade das diferentes mídias, vendida ininterruptamente pelas diversas publicidades e pronunciada pelos discursos políticos, a cidade das narrações jornalísticas e assim por diante. Sendo componente dos jogos mediáticos e políticos, a cidade é descrita parcialmente e está em contraste com seu contra modelo, isto é, a "cidade tal qual como se encontra". Mais especificamente a cidade como se encontra é qualificada opostamente à primeira. A escala dessa cidade é a "inumana", ou "[...] produto coletivo da incapacidade dos indivíduos, cada um por si, de compreender o meio cotidiano como um 'mundo' unificado por sua consciência geográfica" (MONNET, 1999a, p. 121). Ou melhor, considerando a cidade no plural, seriam aquelas grandes cidades em sua dinâmica efervescente se mostrando "[...] parecer fora de proporção para o sujeito individual, habitante ou visitante, que tenta apreendê-las" (MONNET, 1999a, p. 182).

Monnet (1999a) vai mais além e lança a hipótese de que os tomadores de decisão urbanos se encontram geralmente presos no que ele chama de "tentações antagônicas". São duas estas tentações às quais ele se refere: a "tentação demiúrgica" e a "tentação da irresponsabilidade". Estas tentações dão lugar a duas formas caricaturais de cidade, ao mesmo tempo opostas e associadas, o que as tornam um paradoxo.

Ele as desenvolve da seguinte forma: a tentação demiúrgica corresponde à responsabilidade total. Neste caso, o poder totalizador das ações e das leis dá o tom da verdade absoluta. São, por exemplo, o ato criador do arquiteto, do engenheiro, do jurista ou do político os quais produzem não somente a rugosidade ou a geomorfologia artificial da cidade a exemplo do materialmente construído como os edifícios, mas também a imaterialidade das leis e suas aplicações e a totalidade social nas quais estes atores se inserem. Só que a tentação demiúrgica faz com que os usuários ou habitantes da cidade, atuais ou futuros não tenham forças de expressão, pelo fato de que sua força faz com que se pense que são eles que têm a obrigação de se adaptarem ao que estipulam as leis e não o contrário.

Já a tentação da irresponsabilidade aparece quando os atores ditos qualificados do ordenamento urbano (técnicos) afirmam que seu gesto e palavra estão num campo restrito o qual é definido por eles próprios. Então, a tentação da irresponsabilidade faz com que os habitantes e os usuários comuns não tenham nada a dizer e fiquem de fora dos processos sociais por lhes passarem a ideia de que a realidade técnica é uma realidade que não faz parte da competência do cidadão comum. Dessa forma, vê-se que, de um lado "[...] uma competência absoluta [demiúrgica] não deixa lugar a nenhuma outra competência; de outro, a 
fragmentação de todas as competências reconhecidas [irresponsabilidade] não permite nenhuma outra intervir no seu campo comum. Em todo caso, está-se numa lógica de competência exclusiva, cujo campo pode ser estreito ou amplo" (MONNET, 1999a, p. 101). No sentido de ampliar suas reflexões, ele passa a discutir, dessa forma, o que considera sobre urbanismo e urbanidade.

\section{A cidade entre urbanismo e urbanidade}

Nos termos de suas reflexões, Monnet (2005) abre discussão sobre a diferença do que ele entende sobre os conceitos de urbanismo e urbanidade. Para que o primeiro termo, o urbanismo, se torne mais evidente e compreensível ele o considera como objeto e não como disciplina. Neste sentido, o urbanismo é aquele da organização social, resultado do sistema social dos atores. Os atores obedecem a uma escala, hierárquica ou não. São considerados atores todos aqueles que participam das ações que interferem de alguma forma no sistema da cidade a exemplo dos políticos, dos comerciantes, dos engenheiros, arquitetos, moradores comuns etc.

Todos os atores, recorrendo às suas próprias concepções, produzem conceitos e objetos sobre e na cidade. Para Monnet (2005), estes conceitos e objetos são realidades e resultados de processos históricos e culturais os quais mudam com o tempo e com os sistemas de valores vigentes a cada época e sociedade. Quando se estuda uma determinada cidade, postula-se sua apreensão observando as particularidades no espaço-tempo. Dessa forma, ele classifica a cidade como "objeto sócio espacial identificável" (OSSI) nos seguintes termos: o espacial representa o "objetivo" (material), aquilo que é exterior às pessoas. O social representa o "subjetivo" (o ideal) o qual não pode ser exteriorizado por que forma parte das pessoas e as pessoas formam parte do subjetivo.

Ele chama a atenção para o fato de que essas considerações possam ser entendidas e levadas para uma visão dualista absolutista. Esta visão sofre severas críticas por ser considerada muito reducionista e inoperante no sentido de se compreender uma totalidade da realidade, pois, ao se desassociar o objetivo do subjetivo ou o espacial do social, pode-se chegar a resultados artificiais. A teoria para se alcançar uma superação desse dualismo radical é a de que não há subjetivo sem a consciência do objeto como não há objeto sem a consciência que o apreende, que o reconhece. Portanto, recorrendo ao termo "trajetiva", Monnet (2005) chega à conclusão de que "[...] a cidade existe porque há sujeitos que a concebem como objeto social e espacial ao mesmo tempo [...] ou seja, a cidade é "[...] uma 
vinda e ida entre o objetivo e o subjetivo, o material e o ideal" (MONNET, 2005, p. 2). A proposta do autor é seguir esta reflexão com o objetivo de não reduzir a cidade nem ao objetivismo e nem ao subjetivismo isolados, e sim, reconhecê-la em sua realidade trajetiva.

Para compreensão do segundo termo "urbanidade", é preciso que se recorra à sua etimologia no sentido de fornecer um sentido mais adequado. A palavra urbanidade é proveniente do latim urbanitas, cujo significado conota: "da cidade, que tem as qualidades do homem da cidade", possui também o sentido de "polidez", "maneira de afabilidade" e "uso o mundo" (MONNET, 1996). Estas noções fazem-no perceber que elas poderiam reconstituir uma "maneira de ser" na cidade - o conjunto de laços sociais existentes ou se criando na cidade - e mostrar o sentido de urbanidade opondo-se tanto às tradições sociológicas quanto às geográficas cujas perspectivas têm considerado a urbanidade maneiras de "fazer ou agir". Essa "maneira de ser", diferenciada do fazer ou agir está equiparada à noção de "relação", pois a identificação dos lugares tanto pelos sujeitos individuais quanto pelos sujeitos coletivos também faz parte de um processo pelo qual os indivíduos se identificam entre si e reciprocamente. Desta forma,

A noção de urbanidade pode ser útil [...], porque ela conduz à ideia de que
"ser na cidade" corresponde indissociavelmente a uma sociabilidade (a arte
de viver em sociedade, as "boas" maneiras, a polidez, a polícia e a política) e
a uma espacialidade (a capacidade de interpretar as informações
provenientes do mundo exterior ou objetivo, a arte de se situar, de se
orientar, de tirar partido dos recursos do ambiente). Finalmente, trata-se de
compreender como se elabora a arte de viver junto: este "junto" implica o
espaço (é necessário estar em um mesmo lugar para estar juntos) e a
sociedade (é necessária a presença dos outros para estar com eles). Como
acabamos de ver, os sujeitos estão implicados na delimitação social e
espacial deste "junto" (para aqueles que estão dentro e/ou para aqueles que
estão fora) (MONNET, 1999a, p. 105).

Portanto, o autor vê a questão da urbanidade como uma questão de pluralidade de existências na cidade o que leva à necessidade de coexistência ou "maneiras de ser" na cidade, ou em escala mais ampla, de "ser no espaço". Se há uma pluralidade de lugares na cidade, há também uma pluralidade de pessoas mantendo relações com seu lugar e com as outras pessoas do mesmo lugar. São pluralidades de urbanidades particulares na cidade ou urbanidades mínimas comuns, como destaca.

Estas urbanidades particulares são ao mesmo tempo regras de vida em grupo e suas aplicações. "Entre a urbanidade individual [...] e a urbanidade coletiva que identifica os 'lugares comuns', [...] há lugar para uma multiplicidade de urbanidades coletivas particulares [...]" (MONNET, 1999a, p. 105). Mesmo porque a realidade da cidade, em sua opinião, não se encontra somente nas formas materiais, porém nas práticas urbanas de seus moradores, já que 
“[...] artefatos espacializados expressam algo das intenções e práticas dos atores sociais que os produziram" (MONNET, 2005, p. 8). O conceito de urbanidade, neste sentido, é importante para Monnet pelo fato de ser possível, a partir dele, introduzir o sujeito como escala geográfica. Para tanto ele novamente se ampara no conceito de "médiance". Considera urbanidades como formas de territorialização ou territorialidades particulares ou maneiras específicas de produzir territórios. Levando em conta o termo "médiance" e conceitos chave da geografia como espaço, território, lugar, paisagem e, ainda mais, ambiente e assim por diante, estes devem ser considerados elaborações culturais na relação de um sujeito individual ou coletivo ao seu meio.

Mas outra importante razão em trazer o conceito de "médiance" para seu corpo de análise é a de transformar o "meio" em uma categoria cognitiva, ou melhor, categoria esta que compreende as dimensões espaciais, paisagísticas ou ambientais tanto na perspectiva objetivista física e fatual quanto na perspectiva fenomenológica, ou seja, o sujeito em suas experiências e representações com o meio onde atua cotidianamente.

Isto conduz nossa atenção sobre uma "geografia do sujeito", isto é, sobre as maneiras de interpretar e de ordenar o mundo pelo sujeito, que se trate de um indivíduo3 ou de uma coletividade. O que nos interessa aqui é o sujeito geográfico, o sujeito que "geo-grafia" o mundo [...]. Este sujeito é geográfico no que ele geografia seu mundo, isto é, que o descreve produzindo-o e o produz descrevendo-o: desse ponto de vista, o sujeito geográfico é um ator e, ainda mais, é coletivo, isto é, que age massivamente sobre o mundo. Se se coloca um meio como uma relação que não depende da consciência para se estabelecer, como uma interação não necessariamente identificável, um mundo, que por seu lado, aparece então como aquele que é identificado pelo sujeito [...] (MONNET, 1999a, p.107).

Como já exposto, para o autor, as cidades são objetos socioespaciais identificáveis e ainda, cidades objetos socioespaciais com multiplicidades de escalas. Considera a urbanidade como um modo de socialização/espacialização específica da cidade, porém envolta em uma problemática que a geografia ainda não conseguiu solucionar, ou seja, a questão do indivíduo em sua corporeidade e sua consciência na escala geográfica. É este um dos pontos centrais de suas interrogações vista a seguir.

\section{A problemática do sujeito como escala geográfica e sua presença na cidade}

Quando Monnet (1999a; 1999b) fala de escala do sujeito em geografia ele quer fazer entender o ser humano como medida das coisas. Isso nos faz relembrar a questão da cidade

\footnotetext{
${ }^{3}$ Monnet chama a atenção no sentido de esclarecer que, quando ele se refere a uma geografia do sujeito ou na escala do indivíduo, não se trata de uma individualidade, do sujeito isolado, e sim, o sujeito indeterminado (quidam) o qual serve de referência ao discurso e representa toda espécie.
} 
abordada anteriormente, a cidade humana em relação à cidade inumana, porém, agora, de forma a explicitar o problema epistemológico apontado por ele: a questão da escala do sujeito em geografia. Para ele existem nitidamente duas escalas. A primeira é a que se refere ao mundo como escala de humanidade, ou seja, todas as cidades seriam, por definição, escala humana. Mas quando se trata da escala do ser humano como indivíduo, ou melhor, quando se trata do olhar da pessoa sobre a cidade, seu meio de vida, neste caso, a grande aglomeração, ela parece estar fora de proporção ou são consideradas "inumanas" para o sujeito individual, seja ele o habitante ou o próprio visitante, os quais mantém contato direto e tenta decifrá-la.

Essa problemática do sujeito como escala resultou em um problema epistemológico para a geografia cuja origem está diretamente relacionada às ciências sociais. As próprias ciências sociais tratam o sujeito individual como um objeto que Monnet chama de "tabu". Para Monnet (1999a) a individualidade geralmente não interessa em seu quadro de reflexão, porém a realidade coletiva. Neste sentido, quando o sujeito é evocado, ele aparece dissolvido geralmente em espécie ou coisa. O sujeito, então, é transformado em indivíduo de comportamento demográfico, estatístico, eleitoral, migratório etc., considera que este mesmo indivíduo poderia "ser um lugar". Tratar o sujeito em termos estatísticos, numéricos, é considerá-lo sem direito à cidade, argumenta.

Neste contexto, as individualidades foram transformadas em "caos" ou "resíduos" e é por meio deles que se procura distinguir os mecanismos, os princípios organizadores e a ordem social. Ao ter considerado o sujeito um "tabu", as ciências sociais e, no caso específico a geografia, deixaram de abordar em suas análises duas realidades consideradas por ele plenamente espacializáveis: a realidade do indivíduo como corpo e o da existência como consciência. Foi tomando esta atitude que

[...] nossas disciplinas [Ciências Sociais e Geografia] adotaram o princípio da "replicabilidade" cara às ciências "duras": o resultado de observação ou de experiência que não poderia ser metodologicamente reproduzida não seria reconhecida como válida. Sendo dado que cada ser humano tem uma característica única, compreende-se que os indivíduos não sejam objetos científicos válidos tanto que eles não são agregados em um "indivíduo" de ordem superior onde emerge uma verdade representativa. O problema, então, é de que há todo um conjunto [...] da realidade que não é jamais estudado: é o caso dos níveis de organização do espaço centrado sobre o indivíduo em geografia (MONNET, 1999a, p. 116).

Este momento de sua reflexão sobre o sujeito individual e o ordenamento espacial é emblemático para a geografia. Ele disserta afirmando que a disciplina tem se especializado em diferentes escalas, graus e níveis de organização espacial. Contudo, ao desconsiderar o sujeito como escala geográfica e campo de análise, levando em consideração o mesmo modo 
como fizeram as ciências sociais, a geografia produziu ferramenta útil para os exercícios de sua competência, construindo indivíduos os quais chama de estéreis. O pensamento e conclusão do autor é a de que ao recusar a escala humana como relação do sujeito no mundo, a geografia esbarra em determinado limite escalar. Assim ela, a geografia, se tornou incapaz de estudar alguns níveis de organização do espaço. Com o objetivo de apresentar exemplo, Monnet faz uma comparação similar entre a Geografia e a Medicina. Diz ele que enquanto a Medicina, considerada "ciência do homem", se transformou aos poucos em "ciência do corpo", estratificando-se vertiginosamente, a Geografia fez trajeto similar, porém em sentido oposto. Da "ciência da natureza", a Geografia se transformou em "ciência da sociedade". Este cruzamento é uma analogia que o autor faz tomando como paradigma o resultado tardio da distinção entre corpo e espírito construído na sociedade moderna do modelo de pensamento cartesiano.

Os resultados deste modelo de pensamento podem ser sentidos hoje verificando a fragmentação quase infinita da ciência médica em especialidades. O ser humano é estudado por regiões cada vez mais específicas, transformado-se em labirinto onde cada parte funciona isoladamente, sem ligação com o restante de sua constituição. Assim define o geógrafo: da mesma forma como a Medicina progressivamente perdeu seu "humanismo", a Geografia perdeu seu "naturalismo", pois voltou seus estudos considerando a sociedade como um conjunto e apropriando-se do ambiente, essencialmente, pelo ângulo econômico.

O geógrafo considera não haver hoje mais espaço para seguir cegamente as infinitas distâncias dicotômicas sujeito/objeto, espírito/corpo, indivíduo/coletividade dado que novas perspectivas epistemológicas como as das concepções sistêmicas e ecológicas e o desenvolvimento das ciências cognitivas, por exemplo, defendem a abolição desse dualismo. Ele aponta Guy Di Méo como um dos raros geógrafos dessa linha de pensamento por considerá-lo o pesquisador que mais se aproxima da escala do indivíduo em suas abordagens na Geografia Social e recupera novamente o pensamento de Augustin Berque defendendo-o de forma justa quando este trata o meio como uma "médiance", o meio como uma "relação", ou trajetória sujeito/objeto, instituição de um para o outro no seio deste meio.

Considera que a proposta de introduzir o sujeito como escala geográfica poderia fornecer subsídios aos geógrafos em conceber a escala corporal nas esferas "sublocais" ou em "nanoescalas". As possibilidades de pesquisas nesta linha seriam diversas, principalmente no campo das ciências cognitivas da qual ele se interessa por que "[...] o indivíduo, que não deveria mais ser considerado como um sujeito/espírito distinto do corpo/objeto como na época moderna, parece fornecer uma escala interessante para aproximar os processos 
cognitivos" (MONNET, 1999a). E como se daria a questão da cognição na cidade e no urbano? Verificaremos a partir de agora.

\section{Consciências geográficas e a cognição na cidade e no urbano}

Monnet (1999a) diz que somos portadores de duas dimensões geográficas: a primeira seria a consciência geográfica primordial, ou seja, a comum a todos os seres humanos. Somos, portanto, possuidores de uma geografia pessoal pelo motivo de que cada um de nós tem uma relação individual com o mundo por intermédio de nossa consciência. Então, consciência de si e consciência do mundo andam juntas. Poder-se-ia pensar que essa seria entendida mais uma vez como uma visão dualista cartesiana da modernidade absolutista com suas esferas autônomas ao se dizer como Descartes o fez: "penso, logo existo". Ao contrário ele prefere ajustar o termo e construir seu próprio pensamento e falar: "eu é o centro de seu mundo". Considera que, a partir daí, deixa-se uma fórmula "absolutista" e passa-se a uma "relacional", ou seja, a do ser-no-mundo. Dessa maneira, a partir da visão relacional, reconhece-se a diversidade partindo da ideia de que o sujeito existe senão para o objeto, de uma identidade vai-se para a alteridade, do centro para a periferia e, finalmente, é a existência de um para o outro. A importância dessa dimensão é permitir o desenvolvimento de todos os particularismos, da escala mais individual a mais coletiva observando-se a gradiente de comunicabilidade e de experiência específicas, pois todos têm suas experiências únicas de serno-mundo. Além do mais, são nas singularidades das experiências que se forma toda matéria de comunicação, tornando mais rica e complexa estas experiências. Isto vai ocasionar a aproximação da experiência de um à experiência do outro. Toda essa intrincada relação vai também explicar o aparecimento de algumas condutas: por exemplo, os laços afetivos e afeições constituídas entre os grupos e hierarquias como a família, os amigos, a comunidade, o país e assim por diante.

A segunda dimensão está relacionada às mediatizações corporais ou sensoriais da relação do ser com o mundo. Traz como exemplo, a questão da visão, que, no caso da Geografia, foi concebida como o mais nobre dos sentidos humanos considerando o conceito de paisagem. Ele mostra que ao longo da história da geografia houve uma inclinação natural da percepção orgânica do espaço e, neste sentido, a visão passou a ser uma dimensão essencial da experiência social do ambiente. De outra forma, Monnet explica que as ciências cognitivas também mostram como os indivíduos fazem a elaboração visual do espaço usando dois sistemas de referência a serem aqui apresentados: $O$ primeiro sistema é denominado de egocêntrico, ou seja, quando o ambiente é representado em relação ao sujeito. O segundo é o 
alocêntrico quando o ambiente é representado relativamente para ele próprio. No primeiro caso, permitir-se-ia fazer uma análise pragmática, produzindo ele próprio, "representações motrizes". No segundo caso, é possível uma análise "semântica" produzindo "representações perceptuais conscientes" Para ele, a combinação dos dois condicionaria a eficácia da ação no ambiente. Através destas perspectivas cognitivas aplicadas à geografia, o geógrafo poderia obter pistas de respostas a alguns questionamentos sobre o indivíduo em diferentes níveis geográficos. Monnet propõe exemplificar: o geógrafo poderia pesquisar qual a representação perceptual que o indivíduo faz de sua casa ou de sua rua, ou em perspectiva mais ampla, como esse indivíduo veria seu bairro, sua cidade ou seu país. A tarefa é saber como objetos sócio espaciais (OSSI - as cidades) se tornam identificáveis diferenciando-se o contexto da identificação pela denominação da identificação sensorial do visual.

Uma condição vantajosa percebida por ele ao se utilizar a escala do indivíduo na geografia é a de que ela conduz a ver tipos diferentes de espaços. Por exemplo, a geografia distingue a extensão do território por uma visão geométrica euclidiana reticular ou areolar e, ao mesmo tempo, o lugar como espaço individualizado, isolado. Porém, segundo Monnet, tais distinções remetem a determinados entendimentos coletivos do espaço que vai diferenciar o espaço do sujeito, porque o meio do sujeito é vivido concomitantemente na experiência do espaço-tempo e, dessa forma,

[...] o lugar pode ser visto como espaço da realidade sensível, ou espaço do presente e da minha presença; o território é a representação de todos os meus lugares de experiência passada (memória) ou do futuro (antecipação para ajuda do corpo social de representações geográficas existentes), então a concretização da permanência; a infinidade da extensão, esta seria a inconcebível eternidade (MONNET, 1999a).

Ele faz um relato anedótico no sentido de mostrar as consequências práticas do urbanismo e do ordenamento territorial urbano quando este se esquece do sujeito em suas análises. Primeiro traça metaforicamente o perfil da arquitetura modernista considerando que ela transformou a moradia em caixas de habitar uniformizada, reduzindo o sujeito a "módulos" assexuados. Ao mesmo tempo o ordenamento urbano transformou a circulação na cidade exclusivamente em problema de tráfego automobilístico. Eis o paradoxo da cidade e do urbano: nos dois casos o sujeito assume forma homogênea ou desaparece no caos. Esses exemplos, para ele, não tem a intenção de fazer com que se pleiteie o desaparecimento ou abandono das outras categorias analíticas da Geografia. Muito pelo contrário, ele propõe, apenas, o que chama de refinamento geográfico e que esse refinamento se aproprie da escala do indivíduo. 
Para dar conta do universo do indivíduo ou do sujeito na Geografia, mas que seja capaz ao mesmo tempo de verificar a variabilidade das capacidades orgânicas, das capacidades quase geométricas do espaço e dos sistemas sociais de interpretação e de ordenamento do mundo no sentido do condicionamento de orientação dos indivíduos e das coletividades nos diferentes meios, ele propõe a multidisciplinaridade, ou melhor, propõe combinar resultados da psicologia da cognição ou da percepção com os da proxemia, da semiologia ou semiótica do espaço, bem como da arquitetura. Em alguns de seus estudos, ele utiliza essa multidisciplinaridade no intuito de elaborar uma geografia da orientação.

\section{Considerações gerais}

No domínio da geografia, diversas correntes teóricas foram elaboradas no sentido de estabelecer critérios para o entendimento da cidade, do urbano e sua dinâmica; a geografia da cidade funcionalista, a geografia dos lugares centrais, a geografia da cidade como organização do espaço para as interações sociais, a geografia behaviorista, a geografia das representações e a geografia fenomenológica são exemplos marcantes relacionadas ao consumir, ao possuir, ao perceber, ao representar, ao ver, ao sentir, enfim, ao viver a cidade.

O que pudemos perceber nas obras levantadas para este artigo é que as reflexões de Monnet amplia e aprofunda o conhecimento da sociedade citadina e urbana por intermédio da análise do fenômeno espacial. Possibilita a ampliação dos objetos de estudo em geografia urbana e sua associação com disciplinas afins. Deste modo, ele delineia caminhos teóricos analíticos capazes de destrinchar as espacialidades e territorialidades envoltas na pequena, na média e, principalmente, na cidade metrópole mundial.

O pensamento de Jèrôme Monnet vem se juntar aos de outros muitos geógrafos ao procurar trazer novas abordagens e teorias em geografia. Dessa forma, ele contribui para o fortalecimento da disciplina que, ao longo do tempo, vem sendo enriquecida por pesquisadores comprometidos com o engrandecimento dessa ciência do espaço. Monnet mostra como a geografia pode abranger questões que podem contribuir de forma inovadora com a questão citadina e urbana.

\section{Referências bibliográficas}

BERQUE, Augustin. Les raisons du paysage: de la Chine antique aux environnements de synthèse. France: HAZAN, 1995. 
MONNET, Jérôme. Urbain, civil et poli. La matrice terminologique de nos réflexions sur la ville. In: Irdb.fr, 1996. Mis en ligne en janvier 2007. Disponível em: http://www.lrdb.fr/articles.php?lng=fr\&pg=146>. Acesso em: 14 jan. 2010.

MONNET, Jérôme. Interpréter et aménager : eléments d'une géographie de la relation au monde. Dossier de canidacture à l'habilitation à diriger les recherches. Paris, 1999a. In : Halshs(Hyper Article en Ligne - Sciences de l'Homme et de la Société)-00006770, version 1 6 Dec 2005. Disponível em : <http://hal.inria.fr/docs/00/05/08/13/PDF/Monnet-HDRvol1.pdf $>$. Acesso em : 22 mar. 2012.

MONNET, Jérôme. Images de l'espace à Los Angeles: éléments de géographie cognitive et vernaculaire. In: Communication au Colloque de l'Institut universitaire de France. "Espace(s)", Toulouse, 1999b. P. 1-28. Disponível em: < http://webast.ast.obsmip.fr/people/rieutord/IUF_conf/actes.html>. Acesso em: 19 nov. 2010. MONNET, Jérôme. From urbanism to urbanity: a dialogue between Geography and Archeology about the city. In: halshs-00007110, version 1 - 12 Dec 2005. P. 1-15. Disponível em: < http://halshs.archives-ouvertes.fr/docs/00/05/16/70/PDF/02urbameso-monnet-eng.pdf $>$. Acesso em: 22 set. 2010.

Recebido em 09 de fevereiro de 2015.

Aceito em 10 de dezembro de 2017. 